\title{
Angiogénesis y neoplasias
}

Khosravi Shahi P. Angiogénesis y neoplasias. An Med Interna (Madrid) 2006; 23: 355-356.

La angiogénesis es el proceso mediante el cual se forman nuevos vasos sanguíneos a expensas de un lecho vascular preexistente. En este proceso las células endoteliales son las principales artífices. Dichas células constituyen una monocapa que tapizan el interior de la luz de los vasos sanguíneos, y que se encuentran en íntimo contacto con la lámina basal (matriz extracelular), que a su vez mantiene una relación estrecha con las células musculares lisas (pericitos) y con el tejido conectivo circundante.

La angiogénesis es un proceso esencial tanto para el crecimiento tumoral como para el desarrollo de metástasis a distancia (diseminación hematógena). Son múltiples los procesos que regulan la angiogénesis, sin embargo se considera que el factor de crecimiento endotelial vascular (VEGF) tiene un papel central en la angigénesis tumoral (1).

El VEGF, también conocido como VEGF-A, es una glicoproteína homodimérica de $45 \mathrm{kDa}$, que actúa como molécula clave en la angiogénesis, puesto que estimula el crecimiento de las células endoteliales vasculares. Esta relacionada con otras moléculas como VEGF-B, C y D y PIGF. Esta glicoproteína es capaz de unirse al receptor VEGFR-1 (estimulando la angiogénesis) y VEGFR-2.

Se han identificado 3 tipos de receptores VEGFR-1, 2 y 3, con distintas funciones biológicas. El VEGFR-1 y VEGFR-2 se localizan en las células endoteliales vasculares, en las células dentríticas y en determinadas células tumorales, mientras que el VEGFR-3 se halla en las células endoteliales linfáticas. De este modo, el VEGF interviene tanto en la regulación de la angiogénesis, como en la linfangiogénesis.

La importancia de la angiogénesis en el desarrollo tumoral, ha llevado a la creación de múltiples fármacos con actividad antiangiogénica, algunas de las cuales ya han demostrado su eficacia en el tratamiento oncológico tanto en monoterapia, como en su combinación con los esquemas de quimioterapia.

Entre estos fármacos antiangiogénicos cabe destacar bevacizumab, sorafenib y sunitinib. Aunque, hay otros muchos fármacos antiangiogénicos en fase de investigación como ZD6474, AZD2171 o AG-013736.

Bevacizumab (Avastin ${ }^{\circledR}$ ) es un anticuerpo monoclonal anti-VEGF que ha demostrado su eficacia en numerosos estu- dios clínicos en el tratamiento del cáncer colorrectal metastático en combinación con 5-Fluoruracilo/leucovorin por vía intravenosa (2) o con 5-Floururacilo/leucovorin/irinotecán intravenosos en primera línea del tratamiento (3). En febrero de 2004 fue aprobado por la Food and Drug Administration (FDA) de los Estados Unidos para su empleo en el cáncer colorrectal metastático, y posteriormente por la Agencia Europea del Medicamento (EMEA) y las autoridades sanitarias españolas en enero y julio de 2005 respectivamente. Sin embargo, este fármaco en el futuro inmediato también será usado en el arsenal terapéutico de otras muchas neoplasias, como el carcinoma de células renales, cáncer de mama o cáncer de pulmón no microcítico.

Otros dos nuevos fármacos antiangiogénicos de reciente introducción en el mercado son el sorafenib y el sunitinib, que a diferencia de bevacizumab que es un anticuerpo monoclonal anti-VEGF, son inhibidores de tirosin-kinasas multidiana de administración oral (4).

Sunitinib ha demostrado su eficacia en un ensayo clínico fase III llevado a cabo en segunda línea de tumores del estroma gastrointestinal, más conocido como GIST, que han progresado a dosis elevadas de imatinib o son refractarios al mismo. En este estudio sunitinib demostró aumentar de forma significativa tanto el tiempo hasta la progresión tumoral $(6,3$ vs. 1,5 meses, $\mathrm{p}<0,0001)$, como la supervivencia global con respecto al placebo $(\mathrm{p}=0,00674)$. La tasa de respuesta parcial fue del $8 \%$ con sunitinib.

Este fármaco también parece ser útil en el tratamiento del carcinoma de células renales metastáticos, y muy probablemente en el tratamiento de la leucemia mieloide crónica con cromosoma Filadelfia positivo.

Sorafenib está siendo estudiado en diversos ensayos fase II y III en el tratamiento de carcinoma de células renales metastáticos, carcinoma hepatocelular, melanoma maligno y carcinoma no microcítico de pulmón.

Los efectos adversos de estos 2 inhibidores de tirosinkinasas multidiana son muy similares y generalmente manejables, como fatiga, diarrea, nauseas, estomatitis, dermatitis e hipertensión arterial. Sin embargo, los efectos adversos de bevacizumab pueden llegar a ser más graves. Su efecto 
secundario más frecuente es la hipertensión arterial, y los más graves, que pueden llegar a comprometer la vida del paciente, son la perforación gastrointestinal (2-3\%) y los eventos tromboembólicos tanto arteriales como venosos. Otros efectos secundarios propios del bevacizumab son: la proteinuria o el síndrome nefrótico, retrasos en la cicatrización de las heridas, el sangrado digestivo y otras hemorra- gias como la epistaxis o la hemoptisis (sobre todo en los ensayos clínicos de cáncer de pulmón no microcítico).

\section{P. KHOSRAVI SHAHI}

Servicio de Oncología Médica. Hospital General Universitario Gregorio Marañón. Madrid

\section{Bibliografía}

1. Leug DW, Cachianes G, Kuang WJ, et al. Vascular endothelial growth factor is a secreted angiogenic mitogen. Science 1989; 246: 1306-9.

2. Kabbinavar F, Schulz J, McCleod M, et al. Addition of bevacizumab to bolus 5FU/leucovorin in first-line metastatic colorectal cancer: results of a randomized phase II trial. J Clin Oncol 2005; 23: 3697-705.

3. Hurwitz H, Fehrenbacher L, Novotny W, et al. Bevacizumab plus irinotecan, fluorouracil, and leucovorin for metastatic colorectal cancer. N Engl J Med 2004; 350: 2335-42.

4. Sakamoto KM. SU-11248 SUGEN. Curr Opin Investig Drugs 2004; 5: 1329-39. 